Short Note

\title{
Trimethyl 4,6-Dicyano-5-hydroxybenzene-1,2,3-tricarboxylate
}

\author{
Afsaneh Zonouzi ${ }^{1, *}$, Roghieh Mirzazadeh ${ }^{1}$ and Seik Weng $\mathrm{Ng}^{2}$ \\ 1 School of Chemistry, University College of Science, University of Tehran, Tehran, 14174, Iran \\ 2 Department of Chemistry, University of Malaya, Kuala Lumpur, 50603, Malaysia \\ * Author to whom correspondence should be addressed; E-Mail: zonouzi@khayam.ut.ac.ir.
}

Received: 28 April 2012 / Accepted: 1 August 2012 / Published: 28 August 2012

\begin{abstract}
A novel synthesis of a fully substituted fluorescent phenol by a one-pot reaction of dimethyl acetylendicarboxylate and malononitrile in the presence of catalysts has been developed. The structure of the synthesized compound was assigned on the basis of its elemental analysis, ${ }^{1} \mathrm{H}-\mathrm{NMR},{ }^{13} \mathrm{C}-\mathrm{NMR}$, IR, mass spectral and X-ray data. The photophysical data of the new compound are reported.
\end{abstract}

Keywords: fully substituted phenol; fluorescence; one-pot reaction; malononitrile; dimethyl acetylenedicarboxylate; keto-enol tautomerization

Optoelectronic devices such as optical fibers, switches, tunable lasers and amplifiers, modulators with various applications need compounds emitting in the blue spectral region [1]. Multi-component reactions (MCRs) are of increasing significance in organic and medicinal chemistry. MCRs allow organic compounds to be synthesized in a few steps or in a one-pot operation [2].

Substituted phenols are of great importance in biosynthesis and also as building blocks in organic synthesis [3,4]. There are a few reports on the synthesis of highly substituted phenols [5]. So the development of a multi-component one-pot procedure for the synthesis of fluorescent poly-functionalized phenol can be seen as urgently interesting for technology upgrading. In continuation of our quest for developing one-pot procedures, here we wish to report a novel one-pot condensation reaction of dimethyl acetylenedicarboxylate $\mathbf{1}$ and malononitrile in the presence of $\mathrm{Ph}_{3} \mathrm{P}$ (triphenylphosphine) and $p$-toluenesulfonic acid ( $p$-TSA) for the synthesis of fully substituted phenol 2 with bright fluorescence property (Scheme 1).

Easy, rapid and mild reaction conditions and also high atom economy of this one-pot procedure make the present method useful for the synthesis of highly functionalized phenols. 
Scheme 1. Synthesis of trimethyl 4,6-dicyano-5-hydroxybenzene-1,2,3-tricarboxylate.

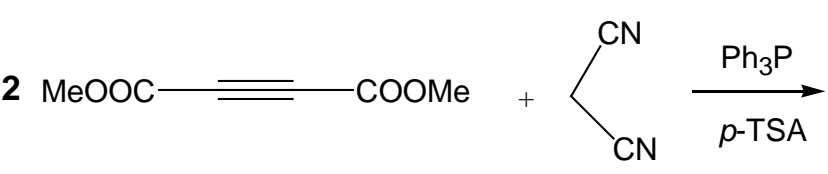

1

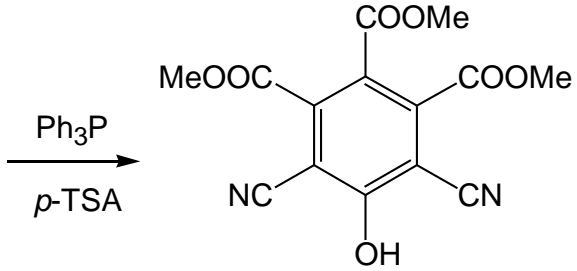

2

Structure 2 was assigned on the basis of its elemental analysis, ${ }^{1} \mathrm{H}-\mathrm{NMR},{ }^{13} \mathrm{C}-\mathrm{NMR}$, IR and mass spectral data. The light green crystals of $\mathbf{2}$ were obtained by slow crystallization from ethyl acetate and its X-ray structure was determined to confirm unambiguously its structure [6] (Figure 1).

Figure 1. X-Ray crystal structure of 2.
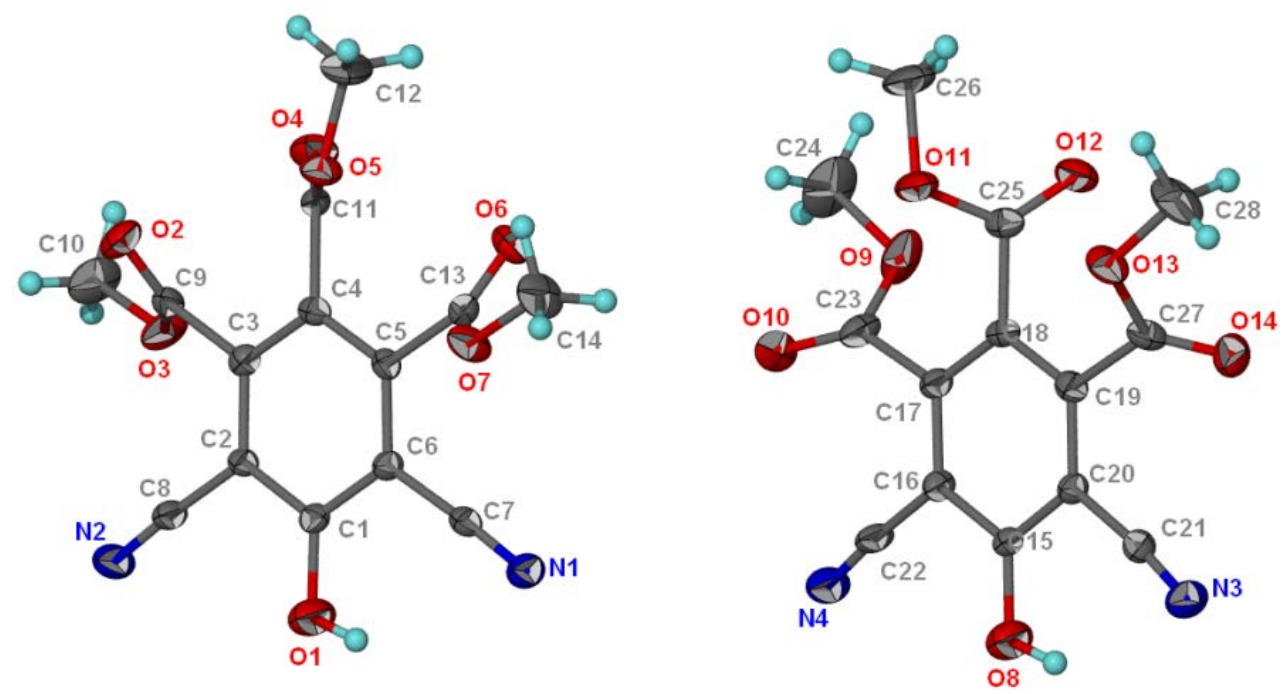

A possible mechanism for the synthesis of $\mathbf{2}$ is shown in Scheme 2. It is suggested that the zwitterion 3 is produced at first by addition of $\mathrm{Ph}_{3} \mathrm{P}$ to the acetylenic ester. Then the zwitterion 3 condenses with another ester molecule to produce zwitterion 4. Attack of the malononitrile anion at 4, fallowed by loss of $\mathrm{Ph}_{3} \mathrm{P}$ and intramolecular cyclization affords 5. Elimination of $\mathrm{CN}^{-}$from $\mathrm{C}_{2}$ and addition of $\mathrm{CN}^{-}$to $\mathrm{C}_{6}$ in the presence of $\mathrm{OTS}^{-}$can produce the intermediate $\mathbf{6}$. Finally, 6 can be aromatized to $\mathbf{2}$ by keto-enol tautomerization. Intermediate $\mathbf{6}$ was detected in the early stage of the reaction by ${ }^{1} \mathrm{H}-\mathrm{NMR}$ and IR spectra. The proton adjacent to the CN group appears at $\delta=4.53$ for 6 in the ${ }^{1} \mathrm{H}$-NMR spectrum and the carbonyl group of $\mathbf{6}$ has been detected at $v_{\max }=1,801 \mathrm{~cm}^{-1}$ in the IR spectrum of the reaction mixture. At the end of this transformation (after $24 \mathrm{~h}$ ), there was no carbonyl absorption detectable in the IR spectrum. Probably, the stability gained from aromatic ring generation drives this keto-enol tautomerization. 
Scheme 2. A possible mechanism for the formation of 2.

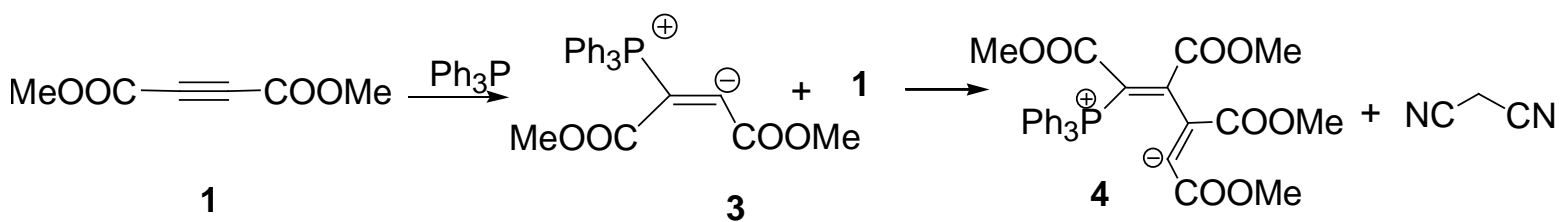<smiles>COC(=O)c1c(C(=O)OC)c(C(=O)OC)c(C(=O)OC)c(C(=O)OC)c1C(=O)OC</smiles>

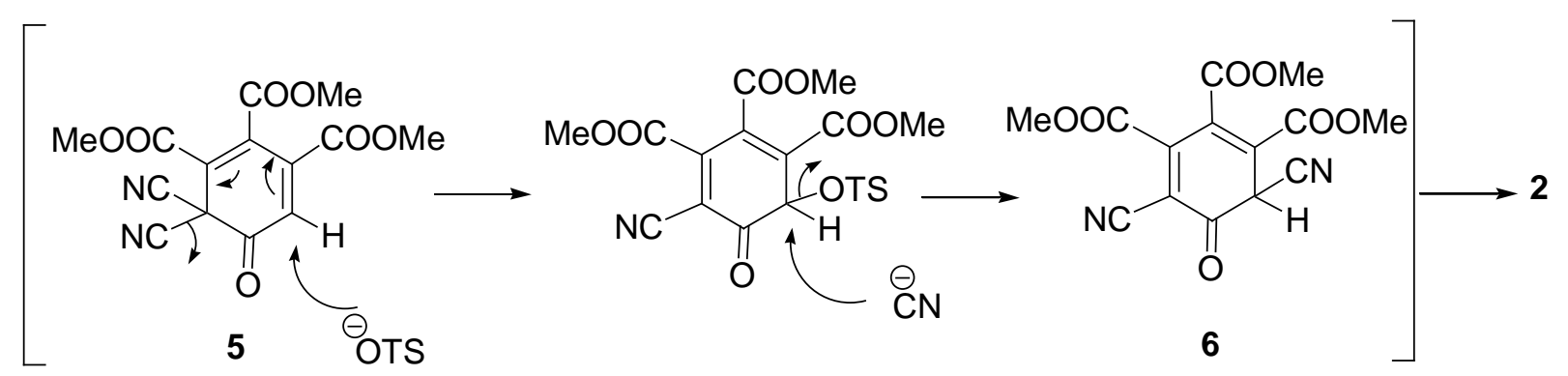

Compound 2 is fluorescent and its photophysical data including $\lambda_{\text {Abs. }}(\mathrm{nm}), \lambda_{\text {Flu. }}(\mathrm{nm})$ have been measured for $0.002 \mathrm{M}$ solutions in $\mathrm{CH}_{3} \mathrm{OH}, \mathrm{CH}_{3} \mathrm{CN}$ and $\mathrm{CHCl}_{3}$ (Table 1).

Table 1. Photophysical data: electronic absorption (Abs.) and fluorescence (Flu.) of 2.

\begin{tabular}{|c|c|c|c|c|c|c|}
\hline & \multicolumn{2}{|c|}{$\mathrm{CH}_{3} \mathrm{OH}$} & \multicolumn{2}{c|}{$\mathrm{CH}_{3} \mathrm{CN}$} & \multicolumn{2}{c|}{$\mathrm{CHCl}_{3}$} \\
\hline Comp. & $\lambda_{\text {Abs. }}$ & $\lambda_{\text {Flu. }}$ & $\lambda_{\text {Abs. }}$ & $\lambda_{\text {Flu. }}$ & $\lambda_{\text {Abs. }}$ & $\lambda_{\text {Flu. }}$ \\
\hline $\mathbf{2}$ & 237 & 469 & 226 & 459 & 335 & 455 \\
\hline
\end{tabular}

Figure 2 shows photographs of compound 2 solutions in $\mathrm{CH}_{3} \mathrm{OH}, \mathrm{CH}_{3} \mathrm{CN}$ and $\mathrm{CH}_{3} \mathrm{Cl}$ (a): under visible light and (b): under a UV lamp with $\lambda=366 \mathrm{~nm}$ (Philips TL8W/08F8T5/BLC).

Figure 2. Photographs of solutions of 2, from left to right in $\mathrm{CH}_{3} \mathrm{OH}, \mathrm{CH}_{3} \mathrm{CN}$ and $\mathrm{CH}_{3} \mathrm{Cl}$, respectively.

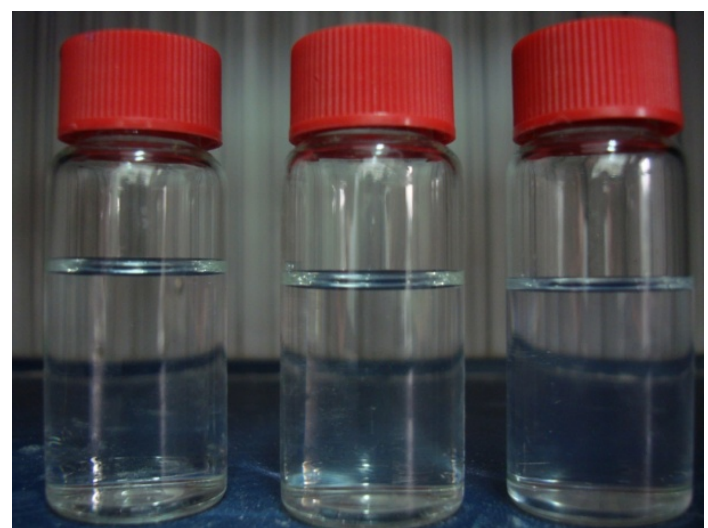

(a)

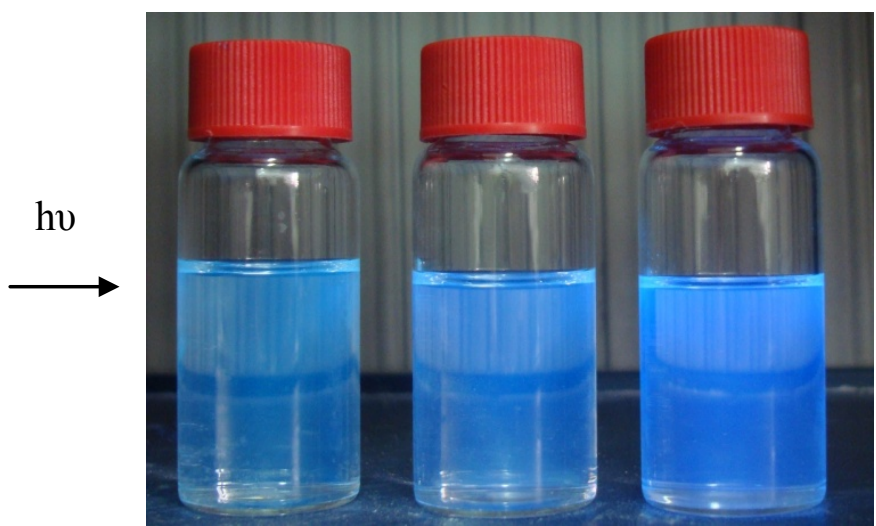

(b) 


\section{Experimental}

Elemental analysis for $\mathrm{C}, \mathrm{H}$ and $\mathrm{N}$ was performed using a Thermo Finnigan Flash EA1112 instrument. ${ }^{1} \mathrm{H}-\mathrm{NMR}$ and ${ }^{13} \mathrm{C}$-NMR spectra were determined on a Bruker 500 spectrometer. IR spectra were measured on a Bruker EQUINOX 55 spectrophotometer with the ATR method. Mass spectra were recorded on a Finnigan-MAT 8430 spectrometer. Photophysical data measurements were made with a Cary Eclipse Fluorescence spectrophotometer.

Trimethyl 4,6-dicyano-5-hydroxybenzene-1,2,3-tricarboxylate (2). To a magnetically stirred solution of dimethyl acetylenedicarboxylatae $(0.28 \mathrm{~g}, 2 \mathrm{mmol})$ in $3 \mathrm{~mL}$ of $\mathrm{CH}_{2} \mathrm{Cl}_{2}, \mathrm{Ph}_{3} \mathrm{P}(0.26 \mathrm{~g}, 1 \mathrm{mmol})$ and malononitrile $(0.1 \mathrm{~g}, 1.5 \mathrm{mmol})$ in $3 \mathrm{~mL}$ of $\mathrm{CH}_{2} \mathrm{Cl}_{2}$ were added dropwise by two dropping funnels at $-10{ }^{\circ} \mathrm{C}$ over $40 \mathrm{~min}$ and stirring was continued at this temperature for $2 \mathrm{~h}$. Then, $0.069 \mathrm{~g}$ (40 mol\%) p-TSA were added. The reaction mixture was warmed up to room temperature and stirred for $24 \mathrm{~h}$. The solvent was removed under reduced pressure and the residue was purified by column chromatography on silica gel, using $n$-hexane/ethyl acetate (3/1) as the mobile phase. The product was obtained as light green crystals, $0.26 \mathrm{~g}, 83 \%$. Melting point: $129-130{ }^{\circ} \mathrm{C}$.

\section{Structural Characterization}

IR, $v_{\text {max }}: 3419,3348,3252,2961,2232,1728,1651,1573,1430,1370,1303,1240,1173,1015 \mathrm{~cm}^{-1} ; \delta_{\mathrm{H}}$ (500 MHz, $\left.\mathrm{CDCl}_{3}\right): 3.78\left(3 \mathrm{H}, \mathrm{s}, \mathrm{CH}_{3}\right), 3.91\left(6 \mathrm{H}, \mathrm{s}, 2 \mathrm{CH}_{3}\right), 8.03(1 \mathrm{H}, \mathrm{br} \mathrm{s}, \mathrm{OH}) \mathrm{ppm} ; \delta_{\mathrm{C}}(125 \mathrm{MHz}$, $\left.\mathrm{CDCl}_{3}\right)$ : 54.2, $54.6\left(\mathrm{CH}_{3}\right), 96.5(\mathrm{CN}), 113.9,114.2,114.4,155.0$ (Ar), 163.7, 165.8 (CO) ppm; MS: $\mathrm{m} / \mathrm{z}=318\left(\mathrm{M}^{+}\right), 317,214,156,141,59,45$; Anal. Calcd for $\mathrm{C}_{14} \mathrm{H}_{10} \mathrm{~N}_{2} \mathrm{O}_{7}: \mathrm{C}, 52.84 ; \mathrm{H}, 3.17$; N, 8.80; Found: C, 52.79; H, 3.15; N, 8.62.

\section{Acknowledgements}

Support of this study by the Research Council at the University of Tehran is gratefully acknowledged.

\section{References and Notes}

1. Lakowicz, J.R. Principle of Fluorescence Spectroscopy, 3rd ed.; Springer: New York, NY, USA, 2006.

2. Hussain, H.H.; Babic, G.; Durst, T.; Wright, J.S.; Flueraru, M.; Chichirau, A.; Chepelev, L.L. Development of novel antioxidants: Design, synthesis, and reactivity. J. Org. Chem. 2003, 68, 7023-7032.

3. Vosooghi, M.; Rajabalian, S.; Sorkhi, M.; Badinloo, M.; Nakhjiri, M.; Negahbani, A.S.; Asadipour, A.; Mahdavi, M.; Shafiee, A.; Foroumadi, A. Synthesis and cytotoxic activity of some 2-amino-4-aryl-3-cyano-7-(dimethylamino)-4H-chromenes. Res. Pharm. Sci. 2010, 5, 9-14.

4. Wright, J.S.; Johnson, E.R.; DiLiabio, G.A. Predicting the activity of phenolic antioxidants: Theoretical method, analysis of substituent effects, and application to major families of antioxidants. J. Am. Chem. Soc. 2001, 123, 1173-1183.

5. Samshuddin, S.; Narayana, B.; Sarojini, B.K. Ethyl 4,4"-difluoro-5'-hydroxy-1,1':3',1"-terphenyl4'-carboxylate. Molbank 2011, 2011, M745. 
6. Crystallographic data for compound 2 reported in this paper have been deposited with the Cambridge Crystallographie Data Center as supplementary publication CCDC No. 842814. These data can be obtained free of charge via www.ccdc.com.ac.uk/data_request/cif.

(C) 2012 by the authors; licensee MDPI, Basel, Switzerland. This article is an open access article distributed under the terms and conditions of the Creative Commons Attribution license (http://creativecommons.org/licenses/by/3.0/). 